\title{
Determinants of Behavioral Intention in Adopting Network Monitoring System
}

\author{
Shafiq Mugerwa \\ Assistant Systems Administrator \\ (MIS-Unit) \\ Makerere University Business School, \\ Kampala, Uganda
}

\author{
Musa B. Moya \\ Associate Professor \\ Dean Faculty of Computing and \\ Informatics \\ Makerere University Business School, \\ Kampala, Uganda
}

\author{
Geoffrey Mayoka Kituyi \\ Senior Lecturer \\ Computer Science and Engineering \\ Makerere University Business School, \\ Kampala, Uganda
}

\begin{abstract}
Makerere University Business School(MUBS) staff and student population stands to over 15,000 (MUBS HR report 2014) but on average, MUBS digitized online network can support about 700 users pick time and approximately 300 off pick hours which is not sufficient (Management Information Systems Unit Network statistics, 2015). Could the low support be attributed to the determinants of behavioral intention? This study therefore examined the relationships between performance expectancy, effort expectancy, social influence, facilitating conditions and behavioral intentions in the adoption of an integrated network monitoring system (NMS) at Makerere University Business School (MUBS). The study followed a cross sectional quantitative research design that focused on describing and drawing inferences from the findings on the relationship between the variables. The study population comprised of 189 administrative staff using the survey instrument based on the UTAUT constructs tailored for the study. Data was analyzed using descriptive statistics, correlations and regressions analysis using Statistical package for social sciences (SPSS). The results indicate that there were significant positive relationships between Performance Expectancy, Effort expectancy Social influence and Facilitating Conditions on Behavioral intention. Emphasis should be placed on performance expectancy, effort expectancy, social influence and facilitating conditions as determinants of behavioral intention for better network monitoring system.
\end{abstract}

Key words: Network monitoring system, UTAUT, behavioral intention, performance expectancy, effort expectancy, social influence and facilitating conditions. 


\section{INTRODUCTION}

Network Monitoring Systems (NMSs) are essential in managing the complex computer networks of today. They ensure all faults on the network are known and assist the network operator in fixing these faults. They involve the collection of tools integrated in a single operator interface with a powerful but user-friendly set of commands for performing most or all network management tasks (Stallings, 2007).

Currently, MUBS network is managed by the dynamic host control protocol (DHCP) server and the cyber roam. In an incident where either the cyber roam is off or the DHCP server, it is hard to detect which equipment are connected on the network and which one is offline.

The failure to adopt a network monitoring tool by many staff in MUBS is of particular concern. Most of the studies on innovation in higher education have centered on ICT software and hardware designs that are driven from information science (IS) or information technology (IT) perspective of behavioral intention to use the system on an individual Level (Fishbein \& Ajzen, 1975; Venkatesh \& Davis, 2000), (Venkatesh 2012), (Moya et.al 2016; Engotoit et.al 2016; Lukwago et.al 2016; 2017; Nyesiga et al. ,2017; Moya et al, 2017).

\subsection{Statement of the problem}

MUBS staff and student population stands to over 15,000 (MUBS HR report 2014) but on average, digitized online network can support about 700 users pick time and approximately 300 off pick hours which is not sufficient (MISU Network statistics, 2015). Could the low support be attributed to the determinants of behavioral intention? This study therefore examined the relationships between performance expectancy, effort expectancy, social influence, facilitating conditions and behavioral intentions in the adoption of an integrated network monitoring system at Makerere University Business School (MUBS).

\subsection{Objectives of the study}

This study focus particularly on the influence of network monitoring system adoption that technology complexity in
MUBS has in relation to the intention to use a new technology. Similarly, the study seeks to establish the relationship between Performance Expectancy, Effort Expectancy, Social Influence and Facilitating Conditions on the Behavioral Intention of adopting a NMS at MUBS. This study was intended to promote significant knowledge on how important monitoring equipment is, beneficial to the academicians and researchers and understanding the role of network monitoring.

\section{THEORETICAL FRAMEWORK AND LITERATURE REVIEW}

The UTAUT is a unified model that was developed by Venkatesh et al (2003) based on social cognitive theory with a combination of eight prominent information technology (IT) acceptance research models. The authors examined the predictive validity of eight models in determining the behavioral intention and usage to allow fair comparison of the models.

There are some analytical models dealt with technology or system adopting problems based on information systems, psychological, or sociological theories.

Owing to these models almost could explain $40 \%$ of the variance in individual intention to adopt technology at least, the follow-up studies met an arduous decision to choose appropriate models or even constructs involved in different models without overlooking important functions obtained from other competing models. Venkatesh, Morris, Davis and Davis (2003) integrated eight models from reviewing past related user acceptance literature to formulate a mix model, referred to as "Unified Theory of Acceptance and Use of Technology" (UTAUT).UTAUT has condensed the 32 variables found in the existing eight models into four main effect and four moderating factors. The combinations of the constructs and moderating factors have increased the predictive efficiency to $70 \%$, a major improvement over previous TAM model rates. Self-efficacy has been shown to influence choices of whether to engage in a task, the effort 
expended in performing it, and the persistence shown in accomplishing it.

The greater people perceived their self-efficacy to be, the more active and longer they persist in their efforts. Computer anxiety has been defined as a fear of computers (ICT) when using one, or fearing the possibility of using ICT, opined that attitudes towards computer are very critical issues. Monitoring the users' attitudes towards computers (ICT) should be a continuous process if ICT is to be used for effective training and learning (Oye \& A.Iahad, January 2012).

Various models were developed, such as the Theory of Reasoned Action (TRA) (Fishbein and Ajzen, 1975) and Technology Acceptance Model (TAM) (Davis, 1989). Each model has its own independent and dependent factors for user acceptance and there are some overlaps (Dillon and Morris, 1996). TAM has failed to provide meaningful information about the user acceptance of a particular technology due to its generality (Mathieson et al., 2001). Consequently, a number of modified TAM models were proposed which are applicable to contemporary technologies (Horton et al., 2001; Chau and $\mathrm{Hu}, 2001$ ).However, to confront some of the limitations and uncertainties that multiple models may pose to researchers the Unified Theory of Acceptance and Use of Technology (UTAUT) model was developed (Venkatesh et al., 2003).

UTAUT has four key constructs (i.e., performance expectancy, effort expectancy, social influence, and facilitating conditions) that influence behavioral intention to use a technology and/or technology use. We adapt these constructs and definitions from UTAUT to the consumer technology acceptance and use context. There are many papers quoted UTAUT model or adopted partial dimensions and added other dimensions along with their own topics to understand new IT purchase/use intentions. Mäntymäki and Salo (2013) proposed an extended UTAUT model to predict the young people's purchasing intention in social virtual world. Gruzd, Staves and Wilk (2012) directly utilized the UTAUT model to interpret and explore how the social media are used in research practices. Martín and Herrero (2012) added innovativeness into original UTAUT model to find out the user's psychological influential factors on the online purchase intention in rural tourism.

\subsection{Performance Expectancy and Behavioral Intention to adopt NMS}

This looks at the degree to which individuals believe that adopting a system will help them improve their job performance. It contains five variables namely; performance expectancy, extrinsic motivation, job-fit, relative advantage and outcome expectations (Venkatesh et al, (2003); Campeau and Higgins, (1995); Davis et al., (1989, 1992); Thompson et al., (1991). Performance expectancy is the strongest predictor of intention and consistent with earlier models tested by Agarwal and Prasad (1998). Users of Information Systems give high regard to the level at which the system is advantageous to them in their daily routine.

The evidences in Davis et al. (1989), Taylor and Todd (1995) and Venkatesh et al (2003) suggest that users have more intention to use a new information technology if this information technology can help improve their work performance. Users believe that using NMS is substantially beneficial to them; therefore, they are willing to adopt the system if the operating process is improved. In MUBS, NMS can increase the efficiency of accessing the systems on the network due to the more relative advantages than the traditional monitoring. With this, the user expectations will be high. Agarwal and Prasad (1998),Venkatesh et al., (2003), Lukwago et al. (2017), Engotoit et al. (2016 ; 2017), Nyesiga et al. (2017) and Moya et al. (2017) have pointed out that users have more intention to use a new information technology if it is easy to operate.

H1. The study hypothesizes that performance expectancy has a positive influence on behavioral intentions to adopt Network Monitoring System.

\subsection{Effort Expectancy and Behavioral Intention to adopt NMS}

Perceived ease of use is the degree of ease associated with the adoption of the Technology (Venkatesh et al., 2003). 
Users of Information Systems are concerned with the ease that is associated with the use of the information system. A complex system or a web interface that is difficult to navigate can make users uninterested in adopting the system or website (Byun \& Finnie, 2011). The issue regarding the level of computer literacy amongst the population can alter the perception of respondents to the ease associated with adopting an information system, because computer savvy users may be indifferent.

In other words it is the level of simplicity associated with a technology. However, Moore and Benbasat (1991) and Davis et al., (1989) defined ease of Use as the degree to which an individual believes that using a particular system would be free of physical and mental effort. The evidences in Agarwal and Prasad (1998), Karahanna et al. (1999) , Venkatesh et al., (2003), Lukwago et al. (2017), Engotoit et al. (2016 ; 2017), Nyesiga et al. (2017) and Moya et al. (2017) suggest that users have more intention to use a new information technology if people important to them think it is necessary for them to adopt the new technology.

H2. The study hypothesizes that effort expectancy has a positive influence on behavioral intentions to adopt Network Monitoring System.

\subsection{Social Influence and Behavioral Intention to adopt NMS}

Social influence is the degree to which one is affected by others to adopt the information system (Venkatesh et al., 2003). Religion, ethnicity, culture, economic status and education determine one's intention to adopt a system and eventually use it. Taylor and Todd (1995) and Venkatesh et al. (2003) have pointed out that users will use a new information technology more frequently and positively if they perceive rich resources for use of this technology. Besides an effective and easy to use information system, endusers might not be obliged to use the system until they are motivated by important others (people) that can influence their attitude and behavior. With the way people's life are molded round role models, public figures, sportsmen and celebrities, an encouragement by such important figures to use the system can motivate users to adopt the use of an information system (Taiwo et al.,2012).

Thompson et al., (1991), Venkatesh et al., (2003), Wu et al., (2010) define subjective norm as the degree, to which users consider that it is necessary for others to adopt NMS, social factors look at degree to which users are affected by a certain group culture to adopt NMS and finally image considers the degree to which users perceive that adopting NMS can increase their personal images. Most studies have established positive relationship between social influence and behavioral intention (Venkatesh et al (2012; 2016), Lukwago et al. (2017), Engotoit et al. (2016; 2017), Nyesiga et al. (2017)).

H3. The study hypothesizes that social Influence has a positive influence on behavioral intentions to adopt Network Monitoring System.

\subsection{Facilitating Conditions and Behavioral}

\section{Intention to adopt NMS}

Venkatesh et al., (2003) refers to facilitating conditions as the degree to which an individual believes that organizational and technical infrastructure exists to support adoption and use of the system. It constitutes of perceived behavioral control and facilitating conditions. The former looks at the ability of the users to adopt the systems and the later looks at degree to which users believe that the existing software and hardware supports their adoption of system in case it is adopted, Thompson et al.,(1991), Venkatesh et al.,(2003), $\mathrm{Wu}$ et al., (2010). Venkatesh and Morris (2000) and Venkatesh et al., (2003) suggest that higher behavioral intention leads to a higher frequency of use of a system. Facilitating conditions have had a positive relationship with behavioral intention as reported by (Lukwago et al.,(2017), Engotoit et al.,(2016; 2017), Nyesiga et al.,(2017)).

H4. The study hypothesizes that facilitating conditions have a positive influence on behavioral intention to adopt the NMS at MUBS.

\subsection{Conceptual Framework}


The conceptual framework is adopted from the Unified Theory of Acceptance and Use of Technology (UTAUT) model (Venkatesh et al, 2003).Venkatesh et al. (2003) proposed an acceptance model combining eight existing tools into one model called the "Unified Theory of Acceptance and Use of Technology (UTAUT)", which has been shown to outperform other models for studying the acceptance of technology. The UTAUT model by Venkatesh et al. (2003) postulates six constructs; performance expectancy, effort expectancy, social influence, self-efficacy, anxiety, and attitude toward using technology. These constructs determine the behavioral intent, whereas another two constructs behavioral intent and facilitating conditions influence the usage behavior of the technology (Moya et.al 2016; Engotoit et.al 2016; Lukwago et.al 2016; 2017; Nyesiga et al. ,2017; Moya et al, 2017).

The figure 1 shows the UTAUT model with the related modifiers (external) variables.

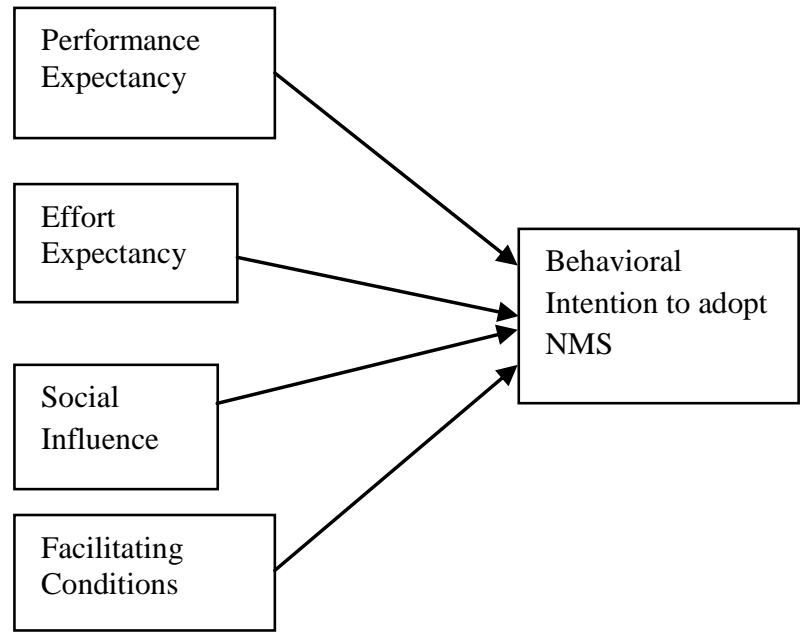

Figure1: Unified Theory of Acceptance and Use of Technology (UTAUT) Model.

Source: Adopted Research model by Venkatesh, Morris, Davis, \& Davis 2003; Venkatesh et al. 2016; Engotoit et al, 2016; Lukwango et al. 2017; Nyesiga et al. 2017; Moya et al, 2016; 2017.

\section{METHODOLOGY}

This brings out the methodology that was used in conducting the research. It entails the research design, the study population, the sampling procedure and sample size, the variables and their measurements, reliability and validity of research instruments, data collection methods and data processing and analysis procedures and techniques.

\subsection{Research Design}

The study took a cross sectional survey design to study the relationships between the quantitative variables of the study. Since the study meant to test rather than generate theory, it adopted a correlational approach which focused on describing and drawing inferences from the findings on the relationships among the study variables.

\subsection{Study Population and Sample Size}

The study population was 189 administrative staff at Makerere University Business School who were directly given questionnaires to respond to the questions. A sample of 126 administrative staff was taken in this study. Krejcie and Morgan (1970) sample size determination table was used and simple random sampling was used in the selection of the sample of 126 where all elements in the population had an equal chance of being selected in the sample. The lottery method of identifying the simple random sample was used.

\subsection{Data collection, Analysis and Presentation}

The data was collected using a pre-coded questionnaire and analyzed using the descriptive statistics analysis method which employs the use of percentages, means and frequencies (Janssens et al., 2008).Statistical Package for Social Scientists (SPSS) was used for data entry and analysis, a linear regression to interpret the degree of relationship between variables. Linear regression analysis helped to provide evidence that the independent variables significantly explain behavioral intentions to adopt NMS.

\subsection{Survey Instruments}

The survey instrument was based on the constructs defined in the UTAUT model by Venkatesh et al. (2003), with the constructs tailored for this study. The study questionnaire was distributed to a total of 140 administrative staff, 133 collected questionnaires, seven (7) were discarded (because the respondents gave more than one answer to a question that 
International Journal of Computer Applications Technology and Research

Volume 7-Issue 03, 139-157, 2018, ISSN:-2319-8656

expected only one answer and or many questions were

unanswered. This meant that the final samples of 126

questionnaires were used for all subsequent analysis. 


\subsection{Measurements of Study Variables}

Items used to measure these study variables were performance expectancy, effort expectancy, social influence, facilitating conditions and behavioral intention. These were adopted from Venkatesh et al., (2003); Lukwago et al. (2017), Engotoit et al. (2016 ; 2017), Nyesiga et al. (2017) and Moya et al. (2017) . Performance expectancy was measured using perceived usefulness, extrinsic motivation, job fit, relative advantage and outcome expectations. Effort expectancy was measured using ease of use, complexity and perceived ease of use. Social influence was measured using subjective norms, social factors and image. Facilitating conditions were measured using perceived behavioral control, conditions and compatibility.

\subsection{Data Reliability and Validity}

A pilot study was conducted to test the validity and reliability of the research instrument. Cronbach's' Alpha was used to calculate and determine the reliability of the items. A Cronbach's alpha value of greater than 0.6 is also considered acceptable (Yong, Hua, \& Mei, 2007).

Cronbach's alpha reliability coefficient for the individual scales to confirm the internal consistency and reliability of measures was calculated and they were above 0.6. Validity of instruments was done in two ways; face validity and content validity. Face validity through getting comments on relevance of the questions to the study variables which were later incorporated in the final instrument. Content validity was also obtained by using Content Validity Index at 0.7742 for expert one and 0.8387 for expert two making an average Content Validity Index of 0.8064 . Since they were all above 0.7 , this means that the questions were all relevant to the study variables as shown in table 1 .
Table 1: Reliability Test

\begin{tabular}{|l|c|c|c|}
\hline Variable & Scale & $\begin{array}{l}\text { Number of } \\
\text { Items }\end{array}$ & $\begin{array}{l}\text { Cronbach's } \\
\text { alpha }\end{array}$ \\
\hline $\begin{array}{l}\text { Performance } \\
\text { Expectancy }\end{array}$ & $1-5$ & 5 & .751 \\
\hline $\begin{array}{l}\text { Effort } \\
\text { Expectancy }\end{array}$ & $1-5$ & 4 & .730 \\
\hline $\begin{array}{l}\text { Social } \\
\text { Influence }\end{array}$ & $1-5$ & 2 & .600 \\
\hline $\begin{array}{l}\text { Facilitating } \\
\text { Conditions }\end{array}$ & $1-5$ & 6 & .711 \\
\hline $\begin{array}{l}\text { Behavioral } \\
\text { Intention }\end{array}$ & $1-5$ & 4 & .726 \\
\hline
\end{tabular}

Source: Primary data

Since the Cronbach's alpha is 0.60 and above, the questionnaire was reliable.

\section{PRESENTATION OF FINDINGS}

The findings of the study were generated from data analysis and its interpretation. It includes descriptive statistics, factor analysis, correlation coefficient analysis and regression analysis. The results were presented in line with research objectives.

\subsection{Demographic Characteristics}

The respondents were categorized under gender, marital status, education, age positions at work and length of service as shown in tables 2, 3,4,5,6 and 7 .

\subsubsection{Distribution by Gender}

The respondents comprised of both female and male majority of which $57 \%$ were male and $43 \%$ were female. This means that most of the sample was taken from the male. This is shown in the table 2.

Table 2: Gender

\begin{tabular}{|l|c|c|}
\hline & Frequency & Percent \\
\hline Male & 72 & 57.1 \\
Female & 54 & 42.9 \\
Total & 126 & 100.0 \\
\hline
\end{tabular}

Source: Primary data 


\subsubsection{Distribution by Marital status}

The respondents were majorly married at $55 \%$ from the total population, single at $42 \%, 2 \%$ cohabiting and $1 \%$ catered for the others. This is shown in the table 3 .

Table 3: Marital status

\begin{tabular}{|c|c|c|}
\hline & Frequency & Percent \\
\hline Single & 53 & 42.1 \\
\hline Married & 69 & 54.8 \\
\hline Cohabiting & 2 & 1.6 \\
\hline Others & 2 & 1.6 \\
\hline Total & 126 & 100.0 \\
\hline
\end{tabular}

Source: Primary data

\subsubsection{Distribution by Education}

Majority of the respondents were Bachelor's degree holders. This meant that many of them were considered to have attained the minimum knowledge for the adoption of a new system. These were followed by Master's degree holders at a percentage of $31 \%$ and followed by Ordinary diplomas at $13 \%$. From the above, this meant that from the sample, the largest population had the knowledge to take on the system. This is shown in table 4.

Table 4: Education attained

\begin{tabular}{|l|c|c|}
\hline & Frequency & Percent \\
\hline Bachelors Degree & 83 & 73.1 \\
Post Graduate Diploma & 4 & 3.2 \\
Masters Degree & 39 & 31.0 \\
Total & 126 & 100.0 \\
\hline
\end{tabular}

Source: Primary data

\subsubsection{Distribution by Age}

The majority of the respondents were between 25-35 years at $65 \%$. These were followed by $21 \%$ at an age between $35-45$ years. Few respondents were seen to be between $45-55$ years and above. This is shown in table 5 .
Table 5: Age of respondents in years

\begin{tabular}{|l|c|c|}
\hline & Frequency & Percent \\
\hline Below 25 years & 12 & 9.5 \\
25-35 Years & 82 & 65.1 \\
35-45 Years & 26 & 20.6 \\
45-55 Years & 5 & 4.0 \\
Above 55 years & 1 & .8 \\
Total & 126 & 100.0 \\
\hline
\end{tabular}

Source: Primary data

\subsubsection{Distribution by Staff category}

Majority of the respondents were administrative assistant at $46 \%$ and the least response was got from directors at $2.4 \%$. This implied that the higher the staff rank, the lower the response. This is shown in the table 6 .

Table 6: Staff category

\begin{tabular}{|l|c|c|}
\hline & Frequency & Percent \\
\hline Director & 3 & 2.4 \\
Deputy Director & 5 & 4.0 \\
Assistant Director & 11 & 8.7 \\
Senior Administrator & 17 & 13.5 \\
Administrator & 31 & 24.6 \\
Administrative Assistant & 59 & 46.8 \\
& 126 & 100.0 \\
\hline
\end{tabular}

Source: Primary data

\subsubsection{Distribution by length of Service with the \\ Institution}

Majority had worked with the institution for a period between 11-15 years at 58\%, followed by those with 6-10 years at $42 \%$. Very few responses were got from staff who worked for more than 16 years at $4 \%$ and $5 \%$. This is showed in table 7. 
Table 7: Length of Service with the institution

\begin{tabular}{|l|c|c|}
\hline & Frequency & Percent \\
\hline 6-10 Years & 42 & 33.3 \\
11-15 Years & 73 & 57.9 \\
16-20 Years & 5 & 4.0 \\
Above 20 years & 6 & 4.8 \\
Total & 126 & 100.0 \\
\hline
\end{tabular}

\section{Source: Primary data}

\subsection{Descriptive Statistics of the Study Variables}

Descriptive statistics for performance expectancy, effort expectancy, social influence, facilitating conditions and behavioral intention were performed using mean and standard deviation as shown in table 8 .

Table 8: Descriptive statistics for study variables

\begin{tabular}{|l|c|c|c|}
\hline & $\mathbf{N}$ & Mean & Std. Deviation \\
\hline Performance Expectancy & 126 & 4.3611 & .60249 \\
Effort Expectancy & 126 & 4.0079 & .58342 \\
Social Influence & 126 & 3.4286 & .89055 \\
Facilitating Conditions & 126 & 3.9947 & .73180 \\
Behavioral Intention & 126 & 4.0893 & .58776 \\
\hline
\end{tabular}

Source: Primary data

There were positive perceptions on performance expectancy $($ Mean $=4.3611)$, effort expectancy $($ Mean = 4.0079), facilitating conditions (Mean $=3.9947$ ), and behavioral intention (Mean $=4.0893)$. This implied that the Network monitoring system is easy to use, useful, and facilitative in terms of infrastructure, can improve performance at work and is usable. However, they were indifferent on social influence $($ Mean $=3.4286)$.

\subsection{Factor Analysis of the Study Variables}

Exploratory factor analysis using principal component and extracting factors or items with factor loadings greater or equal to \pm 0.3 as shown in tables 9 to table 18 .

\subsubsection{Performance Expectancy}

The most important items used to measure performance expectance were three explaining $73.370 \%$ variance as shown in table 9.

Table 9: Performance Expectancy Descriptive statistics

\begin{tabular}{|l|c|c|c|}
\hline & Mean & Std. Deviation & Loadings \\
\hline $\begin{array}{l}\text { Adopting the system } \\
\text { enables me to } \\
\text { accomplish tasks } \\
\text { more quickly. } \\
\begin{array}{l}\text { Adopting the system } \\
\text { increases my } \\
\text { productivity. }\end{array}\end{array}$ & 4.3810 & .65553 & .917 \\
\hline $\begin{array}{l}\text { I would find the } \\
\text { system useful in my } \\
\text { job. }\end{array}$ & 4.4246 & .75118 & .798 \\
\hline Eigen value & & & .850 \\
\hline \% of Variance & & & $\mathbf{2 . 2 0 1}$ \\
\hline
\end{tabular}

Determinant $=.301$

\section{Source: Primary data}

The sample used on performance expectancy was adequate (Kaiser-Meyer-Olkin Measure of Sampling Adequacy = .647, Bartlett's Test of Sphericity Approx. Chi-Square $=$ 147.744, $\mathrm{df}=3$, Sig. =.000). The loadings are well above 0.5 an indication that the three items converged to measure performance expectancy as shown in table 10 .

\subsubsection{Effort Expectancy}

The most important items used to measure effort expectance were three explaining $63.474 \%$ variance as shown in table 10. 
Table 10: Effort Expectancy Descriptive statistics

\begin{tabular}{|c|c|c|c|}
\hline & Mean & $\begin{array}{c}\text { Std. } \\
\text { Deviation }\end{array}$ & Loadings \\
\hline $\begin{array}{l}\text { It would be easy for me } \\
\text { to become skillful at } \\
\text { using the system. } \\
\text { Learning to operate the } \\
\text { system is easy for me } \\
\text {. I would find the } \\
\text { system easy to use in } \\
\text { case I adopt it. } \\
\text { Eigen value } \\
\text { \% of Variance }\end{array}$ & $\begin{array}{l}4.1667 \\
4.1032 \\
3.7540\end{array}$ & $\begin{array}{l}.64187 \\
.74651 \\
.81669\end{array}$ & $\begin{array}{c}.861 \\
.803 \\
.720 \\
\\
\mathbf{1 . 9 0 4} \\
\mathbf{6 3 . 4 7 4}\end{array}$ \\
\hline
\end{tabular}

Source: Primary data

The sample used on effort expectancy was adequate (KaiserMeyer-Olkin Measure of Sampling Adequacy $=.631$, Bartlett's Test of Sphericity Approx. Chi-Square $=76.744$, df $=3$, Sig. =.000). The loadings are well above 0.5 an indication that the three items converged to measure effort expectancy.

\subsubsection{Social Influence}

The most important items used to measure social influence were three explaining $65.174 \%$ variance as shown in table 11.

Table 11: Social Influence Descriptive statistics

\begin{tabular}{|l|c|c|c|}
\hline & Mean & $\begin{array}{c}\text { Std. } \\
\text { Deviation }\end{array}$ & Loadings \\
\hline $\begin{array}{l}\text { People who influence } \\
\text { my behavior think that I } \\
\text { should adopt the } \\
\text { system. }\end{array}$ & 3.2500 & 1.18786 & .859 \\
$\begin{array}{l}\text { Adopting the system } \\
\text { will raise my status } \\
\text { among staff. } \\
\begin{array}{l}\text { Other staffs who wish } \\
\text { to adopt the system will } \\
\text { influence me. }\end{array}\end{array}$ & 3.6389 & 1.01121 & .748 \\
\multicolumn{1}{c|}{$\begin{array}{l}\text { Eigen value } \\
\text { \% of Variance }\end{array}$} & & 1.10330 & .811 \\
\hline
\end{tabular}

Determinant $=.508$

Source: Primary source

The sample used on social influence (Kaiser-Meyer-Olkin Measure of Sampling Adequacy $=.652$, Bartlett's Test of Sphericity Approx. Chi-Square $=83.334, \mathrm{df}=3$, Sig. $=.000$ ). The loadings are well above 0.5 an indication that the three items converged to measure social influence.

\subsubsection{Facilitating Conditions}

The most important items used to measure facilitating conditions were three explaining $66.483 \%$ variance as shown in table 12 .

Table 12: Facilitating Condition Descriptive statistics

\begin{tabular}{|l|c|c|c|}
\hline & Mean & $\begin{array}{c}\text { Std. } \\
\text { Deviation }\end{array}$ & Loadings \\
\hline $\begin{array}{l}\text { The institutional ICT } \\
\text { infrastructure will } \\
\text { support the system. }\end{array}$ & 3.7857 & .91745 & .844 \\
\hline $\begin{array}{l}\text { The institution can } \\
\text { afford to buy the } \\
\text { system. } \\
\begin{array}{l}\text { I have access to the } \\
\text { computer to adopt the } \\
\text { system. }\end{array}\end{array}$ & 3.9286 & .96481 & .811 \\
$\begin{array}{l}\text { Eigen value } \\
\text { \% of Variance }\end{array}$ & 4.2698 & .80660 & .789 \\
\hline
\end{tabular}

Determinant $=.497$

Source: Primary data

The sample used on facilitating conditions (Kaiser-MeyerOlkin Measure of Sampling Adequacy $=.682$, Bartlett's Test of Sphericity Approx. Chi-Square $=86.104$, df $=3$, Sig. $=.000$ ). The loadings are well above 0.5 an indication that the three items converged to measure.

\subsubsection{Behavioral Intention}

The most important items used to measure facilitating conditions were four explaining $61.750 \%$ variance as shown in table 13.

Table 13: Behavioral intention descriptive Statistics 


\begin{tabular}{|l|c|c|c|}
\hline & Mean & $\begin{array}{c}\text { Std. } \\
\text { Deviation }\end{array}$ & Loadings \\
\hline $\begin{array}{l}\text { I intend to update my } \\
\text { computer for the systems } \\
\text { adoption. } \\
\text { I intend to adopt the } \\
\text { system for faster } \\
\text { completion of tasks. }\end{array}$ & 4.0794 & .66457 & .816 \\
\hline $\begin{array}{l}\text { I plan to use the system } \\
\text { to improve my } \\
\text { performance at work. }\end{array}$ & 4.1905 & .68951 & .772 \\
\hline $\begin{array}{l}\text { I intend to adopt and use } \\
\text { the system at work for } \\
\text { the next years. }\end{array}$ & 3.9603 & .85230 & .815 \\
\hline $\begin{array}{l}\text { Eigen value } \\
\text { \% of Variance }\end{array}$ & & & \\
\hline
\end{tabular}

Determinant $=.289$

Source: Primary data

The sample used on behavioral intention (Kaiser-Meyer-

Olkin Measure of Sampling Adequacy $=.741$, Bartlett's Test of Sphericity Approx. Chi-Square $=152.331$, df $=6$, Sig. $=.000$ ). The loadings are well above 0.5 an indication that the four items converged to measure behavioral intention.

\subsection{Diagnostic Tests}

\subsubsection{Normality Test for Study Variables using Skewness and Kurtosis}

The results in table 27 below on skewness indicate statistics ranging from -.077 to -1.842 which is within the recommended range of -2 to +2 implying that the study variables are approximately normally distributed. Kurtosis values range from -.437 to 7.515 which are within the range of -10 to +10 implying that there is a fairly normal distribution as shown in table 14.
Table 14: Skewness and kurtosis

\begin{tabular}{|c|c|c|c|c|}
\hline & Mean & $\begin{array}{c}\text { Std. } \\
\text { Deviation }\end{array}$ & Skewness & Kurtosis \\
\hline & Statistic & Statistic & Statistic & Statistic \\
\hline $\begin{array}{l}\text { Performance } \\
\text { Expectancy. }\end{array}$ & 4.3611 & .60249 & -1.842 & 7.515 \\
\hline $\begin{array}{l}\text { Effort } \\
\text { Expectancy. }\end{array}$ & 4.0079 & .58342 & -1.083 & 4.895 \\
\hline $\begin{array}{l}\text { Social } \\
\text { Influence. }\end{array}$ & 3.4286 & .89055 & -.496 & -.437 \\
\hline $\begin{array}{l}\text { Facilitating } \\
\text { Conditions. }\end{array}$ & 3.9947 & .73180 & -1.147 & 2.485 \\
\hline $\begin{array}{l}\text { Behavioral } \\
\text { Intention. }\end{array}$ & 4.0893 & .58776 & -1.414 & 3.691 \\
\hline
\end{tabular}

\subsubsection{Normality test using Shapiro Wilk}

\section{Statistics}

According to Shapiro wilk statistics, the sig values were greater than 0.05 an indication that the data for all the study variable was approximately normally distributed as shown in the table 15 .

Table 15: Shapiro wilk statistics

\begin{tabular}{|l|c|c|c|}
\hline Shapiro wilk & Statistic & Df & Sig. \\
\cline { 2 - 4 } & .811 & 126 & .187 \\
Performance Expectancy & .900 & 126 & .177 \\
Effort Expectancy & .952 & 126 & .145 \\
Social Influence & .912 & 126 & .162 \\
Facilitating Conditions & .872 & 126 & .225 \\
\hline
\end{tabular}

Source: Primary data 


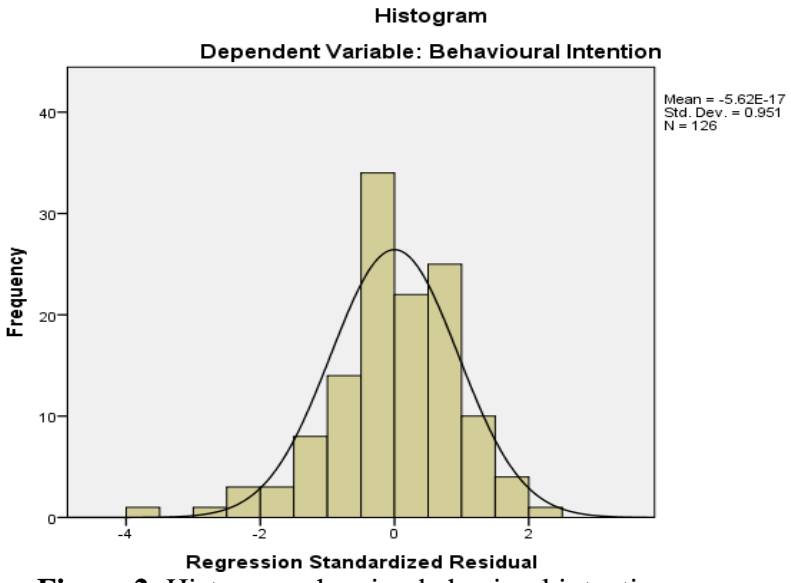

Figure 2: Histogram showing behavioral intention as a dependent variable

\subsubsection{Linearity Test for the Study Variables}

Using the $\mathrm{F}$ statistic values in the ANOVA table, results show that there was a linear relationship between the study variables $(\mathrm{F}=19.436$, Sig $=.000)$. Performance expectancy, effort expectancy, social influence, facilitating conditions and usage predicted $44.7 \%$ of behavioral intention, with performance expectancy (beta $=.194)$, effort expectancy (beta $=-.101)$, social influence $($ beta $=.260)$, facilitating condition (beta $=.418)$ and usage (beta $=-.044)$ as shown in tables 16 , 17 and 18.

Table 16: Model Summary

\begin{tabular}{|c|c|c|c|c|}
\hline Model & $\mathbf{R}$ & $\mathbf{R}$ & $\begin{array}{c}\text { Adjusted R } \\
\text { Square }\end{array}$ & $\begin{array}{c}\text { Std. Error of } \\
\text { the Estimate }\end{array}$ \\
\hline & .669 & .447 & .424 & .44591 \\
\hline
\end{tabular}

Predictors: (Constant), Usage, Effort Expectancy, Social Influence, Facilitating Conditions, Performance Expectancy.

Source: Primary data

Table 17: ANOVA

\begin{tabular}{|l|c|c|c|c|c|}
\hline \multicolumn{1}{|c|}{ Model } & $\begin{array}{c}\text { Sum of } \\
\text { Squares }\end{array}$ & df & $\begin{array}{c}\text { Mean } \\
\text { Square }\end{array}$ & F & Sig. \\
\hline Regression & 19.323 & 5 & 3.865 & 19.436 & .000 \\
Residual & 23.860 & 120 & .199 & & \\
Total & 43.183 & 125 & & & \\
\hline
\end{tabular}

Dependent Variable: Behavioral Intention
Source: Primary data

Table 18a : Regression Coefficients

\begin{tabular}{|c|c|c|c|c|c|}
\hline & B & Beta & $\mathbf{T}$ & Sig. & VIF \\
\hline (Constant) & 1.089 & & 2.947 & .004 & \\
\hline Performance & .189 & .194 & 2.232 & .027 & 1570 \\
\hline Expectancy & & & & & \\
\hline Effort & .102 & .101 & 1.233 & .220 & 1486 \\
\hline Expectancy & & & & & \\
\hline Social & .172 & .260 & 3.596 & .000 & 1132 \\
\hline Influence & & & & & \\
\hline Facilitating & .335 & .418 & 5.010 & .000 & 81 \\
\hline Conditions & & & & & \\
\hline
\end{tabular}

Dependent Variable: Behavioral Intention

Source: Primary data

\subsubsection{Multi co-linearity and Homogeneity test}

Multi co-linearity test was tested using variance inflation factor (VIF).

All VIF were small and less than 2 and this implied that there was no multi co linearity between the independent variables as shown in table 31 .

Homogeneity of variance was tested using ZPRED and ZRISD scatter plot and levene test. The scatter plot indicated data converging towards the right an indication of homogeneity of variance. Also levene statistic was insignificant $(\mathrm{Sig}>0.05)$ an indication that the data was homogeneous.

Table 18 b: Levene Statistic

\begin{tabular}{|l|c|c|c|c|}
\hline \multicolumn{2}{|c|}{ Levene Statistic } & df1 & df2 & Sig. \\
\hline Performance & .098 & 1 & 124 & .755 \\
Expectancy & .167 & 1 & 124 & .684 \\
Effort Expectancy & 5.532 & 1 & 124 & .020 \\
Social Influence & .926 & 1 & 124 & .338 \\
Facilitating Conditions & 2.515 & 1 & 124 & .115 \\
\hline Behavioural Intention & &
\end{tabular}




\subsection{Relationship between Study Variables using}

\section{Inferential Statistics}

\subsubsection{Correlation Analysis}

Correlation analysis was also conducted to establish associations between the study variables.

The results are presented in the table 19.

Table 19: Correlations Matrix of the study variables

\begin{tabular}{|l|c|c|c|c|c|}
\hline & 1 & 2 & 3 & 4 & 5 \\
\hline $\begin{array}{l}\text { Performance } \\
\text { Expectancy (1) }\end{array}$ & 1 & & & & \\
\hline Effort Expectancy (2) & $.487^{* *}$ & 1 & & & \\
\hline Social Influence (3) & .143 & .059 & 1 & & \\
\hline $\begin{array}{l}\text { Facilitating } \\
\text { Conditions (4) }\end{array}$ & $.505^{* *}$ & $.491^{* *}$ & .094 & 1 & \\
\hline $\begin{array}{l}\text { Behavioral } \\
\text { Intention (5) }\end{array}$ & $.475^{* *}$ & $.408^{* *}$ & $.318^{* *}$ & $.579^{* *}$ & 1 \\
\hline
\end{tabular}

**. Correlation is significant at the 0.01 level (2-tailed).

*. Correlation is significant at the 0.05 level (2-tailed).

Source: Primary data

Results in table 19 indicate significant positive relationships between Facilitating Conditions, Performance Expectancy, Effort Expectancy and Social Influence with Behavioral Intention ( $\mathrm{r}=.579 *^{*} ; .475^{* *}, .408^{* *}, .318^{* *} ; \mathrm{p}$-value<0.01). This implied that facilitating conditions positively associated with behavioral intention, performance expectancy associated positively with behavioral intention, effort expectancy positively associated with behavioral intention and social influence associated positively with behavioral intention.

\subsubsection{Regression of Facilitating Conditions,}

\section{Performance Expectancy, Effort Expectancy} and Social Influence with Behavioral Intention.

Using SPSS version 20 hierarchical linear regression models were fitted as shown in table 20 and as Summarised below. Results in table 20, Model 1 Predictors were only control or confounding variables (Constant), Length of service dummy, Lower Education dummy, Gender dummy, under 25 dummy,
Staff Category dummy, Marital Status dummy, Postgraduate dummy, Degree dummy predicted $.3 \%,(\mathrm{~F}=1.052$, Sig=.402) of behavioral intention with Lower Education dummy, Postgraduate dummy, Degree dummy and Staff Category dummy as only significant predictors.

Model 2 Predictors: (Constant), Length of service dummy, Lower Education dummy, Gender dummy, under 25 dummy, Staff Category dummy, Marital Status dummy, Postgraduate dummy, Degree dummy, Facilitating Conditions linearly and significantly $(\mathrm{F}=8.234, \quad \mathrm{Sig}=.000)$ predicted $34.2 \%$ of behavioral intention with Lower Education dummy, Postgraduate dummy, Degree dummy, Staff Category dummy and facilitating condition as significant predictors of behavioral intention.

Model 3 Predictors: (Constant), Length of service dummy, Lower Education dummy, Gender dummy, under 25 dummy, Staff Category dummy, Marital Status dummy, Postgraduate dummy, Degree dummy, Facilitating Conditions, Performance Expectancy linearly and significantly $(\mathrm{F}=8.520$, Sig=.000) predicted $37.6 \%$ with Lower Education dummy, Postgraduate dummy, Degree dummy, Staff Category dummy, facilitating conditions and Performance Expectancy as the significant predictors of behavioral intention.

Model 4 Predictors: (Constant), length of service dummy, lower education dummy, gender dummy, under 25 dummy, staff category dummy, marital status dummy, postgraduate dummy, degree dummy, facilitating conditions, performance expectancy, effort expectancy linearly and significantly $(\mathrm{F}=7.821$, Sig $=.000)$ predicted $37.5 \%$ of behavioral intention with lower education dummy, postgraduate dummy, degree dummy ,facilitating conditions , performance expectancy and effort expectancy as the significant predictors of behavioral intention.

Model 5 Predictors: (Constant), Length of service dummy, Lower Education dummy, Gender dummy, under 25 dummy, Staff Category dummy, Marital Status dummy, Postgraduate dummy, Degree dummy, Facilitating Conditions, Performance Expectancy, Effort Expectancy, Social 
Influence $(\mathrm{F}=8.455, \mathrm{Sig}=.000)$ predicted $41.7 \%$ of behavioral intention with lower education dummy, postgraduate dummy, degree dummy, facilitating conditions , performance expectancy, effort expectancy and social influence as the significant predictors of behavioral intention.

Table 20: Hierarchical Linear Regression

\begin{tabular}{|c|c|c|c|c|c|}
\hline & Model 1 & Model 2 & Model 3 & Model 4 & Model 5 \\
\hline Variables & B & B & B & B & B \\
\hline Constant & $3.056^{* *}$ & $1.548 * *$ & $.706 * *$ & $.437 * *$ & $.420 * *$ \\
\hline Gender & -.050 & -.145 & -.064 & -.053 & -.090 \\
\hline Marital status dummy & .034 & -.003 & .004 & .008 & .009 \\
\hline Lower education dummy & $.929 * *$ & $.703 * *$ & $.958 * *$ & $1.061 * *$ & $.779 * *$ \\
\hline Degree dummy & $.840 * *$ & $.598 * *$ & $.844 * *$ & $.966 * *$ & $.702 * *$ \\
\hline Post graduate dummy & $.916 * *$ & $.722 * *$ & $.962 * *$ & $1.066 * *$ & $.777 * *$ \\
\hline Under 25 dummy & .144 & .039 & .023 & .013 & .029 \\
\hline Staff category dummy & $.266 * *$ & $.210 *$ & $.133 *$ & .112 & .061 \\
\hline Length of service dummy & -.091 & -.104 & -.100 & -.086 & -.081 \\
\hline Facilitating conditions & & $.468 * *$ & $.363 * *$ & $.335 * *$ & $.344 * *$ \\
\hline Performance expectancy & & & $.236 * *$ & $.217 * *$ & $.175^{* *}$ \\
\hline Effort expectancy & & & & .088 & $.168^{*}$ \\
\hline Social influence & & & & & $.145^{*}$ \\
\hline $\mathrm{R}^{2}$ & .067 & .390 & .426 & .430 & .473 \\
\hline Adjusted $\mathrm{R}^{2}$ & .003 & .342 & .376 & .375 & .417 \\
\hline $\mathrm{R}^{2}$ Change & .067 & .323 & .036 & .005 & .043 \\
\hline Sig. F Change & .402 & .000 & .009 & .344 & .003 \\
\hline $\mathrm{F}$ & 1.052 & 8.234 & 8.520 & 7.821 & 8.455 \\
\hline Sig F & .402 & .000 & .000 & .000 & .000 \\
\hline
\end{tabular}

**. Sig <0.01; *. Sig<0.05

Source: Primary data

4.5.2.1 The relationship between performance expectancy and the behavioral intention in adopting the NMS at MUBS.
There was a significant positive relationship between Performance Expectancy and Behavioral Intention to adopt network monitoring system at MUBS $(\mathrm{B}=.175$, sig<0.01) .This implied that a positive change in performance 
expectancy is associated with a positive change in behavioral intention to adopt Network monitoring system by administrative staff at MUBS.

\subsubsection{The relationship between effort expectancy and behavioral intention in adopting} NMS at MUBS.

There was a significant positive relationship between Effort Expectancy and Behavioral Intention to adopt Network monitoring system at $(\mathrm{B}=.168, \mathrm{sig}<0.05)$. This implied that a positive change in effort expectancy is associated with a positive change in behavioral intention to adopt Network monitoring system by administrative staff at MUBS.

\subsubsection{The relationship between social influence} and the behavioral intention in adopting NMS at MUBS.

There was a significant positive relationship between social Influence and Behavioral Intention to adopt Network monitoring system at MUBS $(\mathrm{B}=.145$, sig<0.05). This implied that a positive change in social influence is associated with a positive change in behavioral intention to adopt Network monitoring system by administrative staff at MUBS.

\subsubsection{The relationship between the facilitating conditions and the behavioral intention in adopting NMS at MUBS.}

There was a significant positive relationship between facilitating conditions and Behavioral Intention to adopt Network monitoring system at MUBS ( $\mathrm{B}=.344$, sig<0.01). This implied that a positive change in facilitating conditions is associated with a positive change in behavioral intention to adopt Network monitoring system by administrative staff at MUBS.

\section{DISCUSSION OF FINDINGS}

\subsection{Hypothesis 1: Performance expectancy has a} positive influence on behavioral intentions to adopt NMS.

www.ijcat.com
There was a significant positive relationship between PE and BI to adopt NMS at MUBS .This implied that performance expectancy influenced behavioral intention to adopt Network monitoring system by administrative staff at MUBS. Finding the system useful in my job, adopting the system to enable accomplishing tasks more quickly, increasing staff productivity enhanced the intention to adopt and use the system at work for subsequent years, planned to use the system in improving performance at work, updating computers for the systems adoption and intending to adopt the system for faster completion of tasks.

Therefore, hypothesis 1 is supported, the evidences in Davis et al. (1989), Taylor and Todd (1995) and Venkatesh et al (2003) suggest that users have more intention to use a new information technology if this information technology can help improve their work performance. Users believe that using NMS is substantially beneficial to them; therefore, they are willing to adopt the system if the operating process is improved. In MUBS, NMS can increase the efficiency of accessing the systems on the network due to the more relative advantages than the traditional monitoring. With this, the user expectations will be high. Agarwal and Prasad (1998), Lukwago et al. (2017), Engotoit et al. (2016 ; 2017), Nyesiga et al. (2017) and Moya et al. (2017) have pointed out that users have more intention to use a new information technology if it is easy to operate and Venkatesh et al., (2003) have pointed out that users have more intention to use a new information technology if it is easy to operate.

\subsection{Hypothesis 2: Effort expectancy has a positive influence on behavioral intention to adopt NMS at MUBS.}

There was a significant positive relationship between EE and BI to adopt Network monitoring system at MUBS. This implied that effort expectancy influenced behavioral intention to adopt Network monitoring system by administrative staff at MUBS. Employees ease to become skillful at using the system, easy use of the system if adopted, easy learning to operate the system enhanced the intention to adopt and use the system at work for subsequent 
years, planned to use the system in improving performance at work, updating computers for the systems adoption and intending to adopt the system for faster completion of tasks. Therefore hypothesis 2 is supported, the evidences in Agarwal and Prasad (1998), Karahanna et al., (1999), Venkatesh et al., (2003), Lukwago et al.,(2017), Engotoit et al.,(2016 ; 2017), Nyesiga et al. ,(2017) and Moya et al., (2017) have pointed out that users have more intention to use a new information technology if it is easy to operate suggest that users have more intention to use a new information technology if people important to them think it is necessary for them to adopt the new technology.

\subsection{Hypothesis 3: Social influence has a positive influence on behavioral intentions to adopt NMS at MUBS.}

There was a significant positive relationship between SI and BI to adopt Network monitoring system at MUBS .This implied that social influence influenced behavioral intention to adopt Network monitoring system by administrative staff at MUBS. Peer influence on individual staff behavior to adopt the system, adopting the system to raise status among staff and peers' adoption of the system enhanced the intention to adopt and use the system at work for subsequent years, planned to use the system in improving performance at work, updating computers for the systems adoption and intending to adopt the system for faster completion of tasks.

Therefore, hypothesis 3 is supported, Taylor and Todd (1995) , Venkatesh et al., (2003), Lukwago et al., (2017), Engotoit et al., (2016 ; 2017) and, Nyesiga et al., (2017) have pointed out that users have more intention to use a new information technology if it is easy to operate have pointed out that users will use a new information technology more frequently and positively if they perceive rich resources for use of this technology. Besides an effective and easy to use information system, end-users might not be obliged to use the system until they are motivated by important others (people) that can influence their attitude and behavior. With the way people's life are molded round role models, public figures, sportsmen and celebrities, an encouragement by such important figures to use the system can motivate users to adopt the use of an information system (Taiwo et al.,2012).

\subsection{Hypothesis 4: Facilitating conditions has a positive influence on behavioral intentions to adopt NMS at MUBS.}

There was a significant positive relationship between FC and BI to adopt Network monitoring system at MUBS. This implied that facilitating conditions influenced behavioral intention to adopt Network monitoring system by administrative staff at MUBS. Intention to adopt and use the system at work for the subsequent years, planning to use the system to improve performance at work, Intending to update computers for the systems adoption and adopting the system for faster completion of tasks enhanced the intention to adopt and use the system at work for subsequent years, planned to use the system in improving performance at work, updating computers for the systems adoption and intending to adopt the system for faster completion of tasks.

Therefore, hypothesis 4 is supported, Thompson et al.,(1991), Venkatesh et al.,(2003), Wu et al., (2010). Venkatesh and Morris (2000) ,Venkatesh et al., (2003), Lukwago et al., (2017), Engotoit et al., (2016; 2017) and Nyesiga et al., (2017) have pointed out that users have more intention to use a new information technology if it is easy to operate suggest that higher facilitating conditions leads to a higher frequency of use of a system.

\section{CONCLUSION AND RECOMMENADATIONS}

There was strong influence of performance expectancy, effort expectancy, social influence, facilitating condition on behavioral intention in adopting an integrated network monitoring system. Therefore performance expectancy, effort expectancy, social influence, facilitating condition were determinants of behavioral intention in the adoption of NMS at MUBS in improving network monitoring system.

Performance expectancy should be improved in terms of 
consistence at work, improved productivity and usefulness of the system so as to improve on the behavioral intention of staff to adopt Network monitoring system at MUBS.

Effort expectancy should be improved in terms of clarity of the system to the staff, easiness of the system and simplicity of understanding and operating the system so as to improve on the behavioral intention of the staff to adopt the NMS at MUBS.

Social influence should be improved in terms of raising staff status on the system so as to improve the behavioral intention of staff to adopt the NMS at MUBS.

Facilitating conditions should be improved in terms of institutional ICT infrastructure, ability to purchase the system, access to the computers and hardware so as to improve the intention of the staff to adopt the NMS at MUBS

\section{LIMITATIONS AND AREAS FOR}

\section{FURTHER RESEARCH}

The study was quantitative, therefore need for qualitative study.

The study used cross-sectional approach that gathered the perceptions on the behavioral intention to adopt Network monitoring system, however future research should focus on the longitudinal and experimental research designs to have the in depth understanding of the key predictors of behavioral intentions to adopt the network monitoring system.

This study focused on administrative staff as the unit of inquiry at the same time the unit of analysis. Hence future scholars / researchers should attempt investigate the same phenomenon using academic staff and or public universities as the unit of analysis.

The study particularly focused on the behavioral intention to adopt the networking system in third world setting, further researchers should carry out a comparative research in other developing countries.

www.ijcat.com

\section{REFERENCES}

[1]. Agarwal, R. and Prasad, J. "A conceptual and operational definition of personal innovativeness in the domain of information technology," Information Systems Research, (9:2), 1998. Pp, 204-215.

[2]. Agarwal, R. and Prasad, J. "The role of innovation characteristics and perceived voluntariness in the acceptance of information technologies," Decision Sciences, (28:3), 1997. Pp. 557- 583.

[3]. Alawadhi, S., and Morris, A. "The Use of the UTAUT Model in the Adoption of E- government Services in Kuwait, "Proceedings of the 41st Hawaii International Conference on System Sciences, 2008.

[4]. Alrawashdeh, T. A., Muhairat, M. I., \& Alqatawnah, S. M. (2012). Factors affecting acceptance of web-based training system: Using extended UTAUT and structural equation modeling. ArXiv preprint arXiv: 1205.1904. http://arxiv.org/abs/1205.1904.

[5]. Birth, A., \& Irvine, V. (2009). Preservice teachers' acceptance of ICT integration in the classroom: applying the UTAUT mode.

[6]. Davis, F. D. (1989) "Perceived Usefulness, Perceived Ease of Use, and User Acceptance of Information Technology," MIS Quarterly, (13:3), 1989, pp. 319-339.

[7]. Dishaw, M. T. \& Strong, D. M. (1999). Extending the Technology Acceptance Model with task technology fit constructs. Information and Management, vol. 36, no. 1, pp. $9-21$.

[8]. Engebretsen, T. (2005). Acceptance of Information Technology by Health Research Projects in LowIncome Countries: Intention to Use and Acceptance of Using Epiphany (IUAUE). Master's Thesis. University of Bergen, Norway.

[9]. Engotoit Benard, Mayoka Kituyi Geoffrey, Moya Musa Bukoma, (2016) "Influence of performance expectancy on commercial farmers' intention to use mobile-based communication technologies for agricultural market information dissemination in Uganda", Journal of Systems and Information Technology, Vol. 18 Issue: 4, pp.346-363, https://doi.org/10.1108/JSIT-06-2016-0037Emerald-ISSN: 1328-7265. October, 2016.

[10].Engotoit Benard, Moya Musa, Kituyi Geoffrey Mayoka, Abima Bonface, (2016) “A Mobile-Based Communication Adoption Model for agricultural market information dissemination in Uganda", Global Journal of Computers \& Technology Vol. 
5, No. 1; ISSN: 2394-501X, October, 2016.

[11].Fishbein, M., \& Ajzen, I. (1975). Belief, Attitude, Intention, and Behavior: In an Introduction to Theory and Research Reading. MA: AddisonWesley.

[12].Gandal, Neil, Michael Kende, and Rafael Rob (2000). "The Dynamics of Technological Adoption in Hardware/Software Systems: The Case of Compact Disc Players," Rand Journal of Economics 31: 43-61.

[13].Ghobakhloo, M., Zulkifli, N., \& Aziz, F.(2010). The interactive model of user information technology acceptance and satisfaction in small and medium-size enterprises.European Journal of economics, finance and administrative sciences, (Accessed 18 June 2010).

[14].Gruzd, A., Staves, K., and Wilk, A. (2012). Connected scholars: Examining the role of social media in research practices of faculty using the UTAUT model. Computers in Human Behavior, 28, 2340-2350.

[15].Gubahar, Y. (2008). ICT Usage in Higher Education: A Case study on Preservice Teacher and Instructors. The Turkish Online Journal of Educational Technology, 7(1).

[16].Lukwago Ismail, Musa B. Moya, Keefa Bwiino, Kato Ismael (2017) “Examining Determinants of Behavioural Intention in Adoption of Mobile Money Transfer Services in Uganda", ICTACT Journal on Management Studies Volume: 3 , Issue: 1 February 2017.

[17].Lukwago Ismail, Moya B. Musa ., Kato Ismael, (2016) "Structured Equation Model for Determinants of Adoption and Use of Mobile Money Transfer Services in Uganda", Global Journal of Computers \& Technology Vol. 5, No. 1; ISSN: 2394-501X, October, 2016.

[18].Marchewka, Liu \& Kostiwa 2007. An Application of the UTAUT Model for Understanding Student Perceptions Using Course Management Software, http://www.iima.org/CIIMA/13\%20CIIMA\%2072-07\%20Marchewka\%2093-104.pdf

[19].Moran, M. J. (2006). College Student's Acceptance of Tablet PCs and Application of the Unified Theory of Acceptance Technology (UTAUT) Model. Ph. D. Thesis. Papellas University. Minnesota, USA. Retrieved on 26 Sept. 2007, from:

http://www.homepages.dsu.edu/moranm/Research/ Mark-_for_research_v3.51with_IRB.doc.
[20].Morris, M. G. and Venkatesh, V. "Age differences in technology adoption decisions: Implications for a changing work force," Personnel Psychology, 53, 2000. pp. 375- 403.

[21].Moya Musa , Engotoit Benard , (2017) "Behavioral Intention mediator of performance expectancy and adoption of Commercial farmers' to Use Mobilebased Communication Technologies for Agricultural market Information Dissemination in Uganda", Operations Research Society of Eastern Africa - ORSEA Journal Vol. 7 (1), 2017.

[22]. Moya Musa, Nakalema Eva Stella, Nansamba Christine, (2017) "Behavioral Intention: Mediator of Effort Expectancy and Actual System Usage" Operations Research Society of Eastern Africa ORSEA Journal Vol. 7 (1), 2017.

[23]. Nyesiga Catherine, Kituyi Mayoka Geofrey, Musa B. Moya, Grace Aballo (2017) "Effort Expectancy, Performance Expectancy, Social Influence and Facilitating Conditions as Predictors of Behavioural Intentions to Use ATMs with Fingerprint Authentication in Ugandan Banks" is in GJCST-E Volume 17 Issue 5 Version 1.0

[24].Oye, N. D., A.Iahad, N., \& A.b.Rahim, N. (2012a). Computer Self Efficacy, Anxiety and Attitudes towards Use of Technology among University academicians: A Case Study of University of Port Harcourt- Nigeria. International Journal of Computer Science and Technology. 3(1), 295-301.

[25].Oye, N. D., A.Iahad, N., \& NorZairah, A. (2011). An Application of the UTAUT Model for Understanding Acceptance and Use of ICT by Nigerian University Academicians. International Journal of Information Communication Technologies and Human Development, 3(4), 1-16.

[26].Perez, M. P., Sanchez, A. M., Carnicer, P. L., \& Jimenez, M. J. V. (2004). A technology acceptance model of innovation adoption: the case of teleworking. European Journal of innovation management, 7(4), 280-291.

[27].Pu-Li, J. and R. Kishore, (2006). How Robust is the UTAUT Instrument? A Multigroup Invariance Analysis in the Context of Acceptance and Use of Online Community Weblog Systems. Retrieved on 28 Sept. 2006, from http://portal.acm.org/poplogin.cfm?dl.

[28].Saloner, Garth, and Andrea Shepard (1995). "Adoption of Technologies with Network Effects: an Empirical Examination of the Adoption of Automated Teller Machines." Rand Journal of Economics, Vol. 26(3), pp 479-501. 
[29].Venkatesh, V., Morris, M.G., Davis, G.B., and Davis, F.D, (2003). User Acceptance of Information Technology: Toward a Unified View. MIS Quarterly, 27(3), 425- 478.

[30].Venkatesh, V., and Davis, F. D. (2000) "A Theoretical Extension of the Technology Acceptance Model: Four Longitudinal Field Studies," Management Science (45:2), 2000, pp.342-365.

[31]. Yahya, M., Nadzar, F., Masrek, N., \& Rahman, B. A. (2011). Determinants of UTAUT in Measuring User Acceptance of E-Syariah Portal in Syariah Courts in Malaysia. Paper presented at the 2nd International Research Symposium in Service Management Yogyakarta Indonesia.

[32].Yamin, M., \& Lee, Y. (2010).Level of acceptance and factors influencing students' intention to use UCSI University's e-mail system. Paper presented at the User Science and Engineering (i-USEr), 2010 International Conference. 